\title{
Sustainable Supply Chain Management: Analyzing the Past to Determine a Research Agenda
}

\author{
Warley Henrique Silva ${ }^{1}$, Patricia Guarnieri ${ }^{2, *}$, José Márcio Carvalho ${ }^{1}$, Josivania Silva Farias ${ }^{3}$ \\ and Silvia Araújo dos Reis 4 \\ 1 Post-graduate Program in Agribusiness, University of Brasília, Brasília 70.910-900, Brazil; \\ warleyhsunai@gmail.com (W.H.S.); jmcarvalho1708@gmail.com (J.M.C.) \\ 2 Post-graduate Program in Agribusiness and Post-graduate Program of Management, University of Brasília, \\ Brasília 70.910-900, Brazil \\ 3 Post-graduate Program of Management, University of Brasília, Brasília 70.910-900, Brazil; \\ josivania.mkt@gmail.com \\ 4 Business Department. University of Brasília, Brasília, 70.910-900, Brazil; silviaareis@yahoo.com.br \\ * Correspondence: pguarnieri@unb.br; Tel.: +51-61-107-1402
}

Received: 13 February 2019; Accepted: 8 April 2019; Published: 16 April 2019

\begin{abstract}
The incorporation of sustainable aspects in the supply chain management (SCM) has become an important topic for researchers and professionals; however, it is a field that yet lacks a systemic understanding. The objective of this article is to conduct an analysis on the international literature about the SCM sustainability topic, by employing a systematic review protocol, covering the period from 2011 to 2016. The content analysis technique was performed, following the procedures of categorical thematic analysis proposed by Bardin (1977), which considers the creation of categories a posteriori, based in the direction senses related to the content analyzed. Besides to present the main characteristics of the articles related to distribution of publications per year, most studied sectors, main methods and approaches used main countries and journals of publications, we categorize the results at the systemic approach level of the sustainable development dimensions. We found that some dimensions are prominent when compared with the others: For example: the environmental one, on the other hand, the social one is approached few times in the papers considered in our analysis. These results also indicate that this type of discussion needs to be extended to other sectors that have not yet been explored. The contribution of this paper lies on the synthetization of the state-of-the-art related to sustainable SCM in the period considered, highlighting the environmental, social and economic dimensions, in order to identify a research agenda. By identifying possible research gaps, the results of this research contribute to guide future investigations on sustainable SCM, aiding researchers and practitioners in this field.
\end{abstract}

Keywords: Sustainability; Supply Chain Management; Sustainable Supply Chain Management; Green Supply Chain Management

\section{Introduction}

The transformations and trends observed in society and global markets emphasize the valorization of goods produced in production chains that integrate social and environmental aspects to the economic ones [1]. This phenomenon meets the propositions on the dimensions of sustainable development (economic, environmental and social), which stems from the triple bottom line (TBL) concept [2]. In addition, two other dimensions can be highlighted, the cultural and the political ones [3]. However, for the purposes of this study, we consider the economic, environmental and social dimensions proposed in the TBL concept [2]. 
One of the main challenges that organizations and their production chains are facing is to design production and business models that are capable of not only meeting the demands of consumers but also to have a reduced impact on the environment $[4,5]$.

A strategic way of dealing with this global context of new production trends is based on the adoption of the best managerial practices related to supply chains (SC), addressing sustainability issues [6]. The sustainable supply chain management (SSCM) is recognized as the concept that covers these demands [7] and, is capable to provide the strategic and transparent integration of social, environmental and economic aspects put in place to reach systemic coordination of inter-organizational projects and business processes [7]. The final aim is to improve the supply chain's long-term economic performance. Besides that, this concept may provide operational benefits as well as positive impacts on society [8].

It is important to note that, the understanding of the environmental aspect in the supply chain denotes the use of natural resources and the impacts of actions on the environment, while the social aspect is directed by practices that focus on the health and well-being of people who are directly and indirectly impacted by supply chain business [9].

The increasing importance of this research topic is reflected by the rise of publications during the last years. A theoretical shortage persists in the SSCM area [10], despite its importance. Some authors point out that the sustainability orientation predicts operational performance through advanced but not basic Sustainable supply chains-SSC practices [8]. Another proposes models to test the relationships among sustainability orientation, supply chain integration, sustainable procurement, design and environmental and cost performance [11].

Besides that, it is important to emphasize that other systematic literature reviews on similar topics were already carried out [12,13]. In order to review papers related to environmental sustainability of logistics service providers and point out some research questions to be investigated, [14] performed a systematic literature review (SLR) based on two academic databases (Scopus and Web of Science), covering the period of 1960-2014. Another SLR, found that there is a research gap related to environmental and socio-political factors influencing the adoption of knowledge management in the context of startups [15]. The relationship between sustainability orientation and innovation culture and innovation outcomes in large firms and small firms, through a systematic literature review was performed by [16].

Considering that sustainable aspects incorporated in the supply chain management (SCM) have become a relevant topic for researchers and professionals [17], previous literature reviews on general contexts of sustainable supply chain management were also published by [18-20], focusing on the integration of the three sustainability dimensions. The same is observed related to green supply chain management, which focus on the environmental aspects and was approached by [16,18].

Although several papers have approached sustainable or green supply chain management, based on literature reviews. No one, until this moment, considered the issue of the integration of the three dimensions of triple bottom line, covering the databases: Web of Science, Scopus, Science Direct Online and Emerald. So, the intention of this paper is to complement the previous literature reviews already published, having a main objective to conduct an analysis of the state-of-art related to SSCM topic, considering all dimensions of sustainability, through a systematic literature review, following the protocol proposed by [21], covering the period from 2011 to 2016.

The systematic literature review was chosen, since this procedure establishes well-defined and structured criteria within the process of searching and analyzing information about the topic, in this case considering three main factors: The year of publication, number of citations and impact factor, under a multicriteria decision aid perspective. The use of a systematic review protocol guarantees greater rigor, robustness and replicability to the research [22].

This article summarizes the literature related to this topic, highlighting the sustainability dimensions approached and, presenting the main characteristic of the publications, pointing out the sustainability dimensions addressed, sectors most studied, methods used, distribution per year and 
main countries and journals of publications. This analytical effort contributes to guide future researches by exposing possible research gaps and opportunities.

The structure of this article comprises, in addition to this introduction, six sections. In section two, there are topics that integrate the theoretical framework of this article (supply chain management and sustainability). Section three deals with the methodological procedures adopted in the research, by presenting the systematic review protocol. Section four presents the results, covering the general context of the publications. Section five describes the dimensions of sustainability and its discussions in the articles analyzed in this SLR. Section six discusses the future perspectives in the studies in this field, proposing an agenda for future research. In the last section, we present the final considerations, limitations, contributions and guidance for future research on the SSCM topic.

\section{Supply Chain Management and Sustainability}

One of the most common definitions of the term supply chain was diffused by [23], in which the authors mention that a supply chain is the alignment of firms to make available products to the consumer market. It is a conventional view of supply chain and it is based on a sequential structure, where goods are transported from suppliers to processors, wholesalers, retailers and end consumers.

Another concept determines that supply chain is understood as the aggregate of three or more firms directly involved in the upstream and downstream flows of goods, services, economic resources and information from the source chain to the end customer [24].

Thus, it is perceived that supply chain, understood as a set of integrated firms and their respective relationships requires the adoption of better targeted and synchronized managerial strategies, given the level of complexity involved in this interaction process among firms. The supply chain does not only involve manufacturers, suppliers and sectors responsible for purchases and stock, but also includes carriers, retailers and their own customers [25].

Besides that, SCM comprises the integration of business processes via supply chain, involving the coordination of activities and processes not only within the firm, in isolation, but among the others that compose the supply chain [26].

Among the many definitions of SCM, this paper considers the definition from [24]. In their study, the authors reviewed, classified and synthesized some definitions commonly adopted in academic discussions on supply chain and its management. For them, the supply chain is defined as a group of three or more entities (organizations or individuals) directly involved in the flows of provision and distribution of goods and services, finance and information, from a source to a customer. In general, the authors suggest that the goal of SCM is to seek the synchronization of all supply chain activities in order to create value for customers.

SCM gains greater relevance with the notion that firms must integrate themselves with suppliers and customers strategically, aiming for positive gains, which are not only monetary ones. Thus, the functions associated with each supply chain member, in the context of SCM, seek to achieve purposes that are valuable and creates evolution opportunities for all sides involved, aiming for gain to gain partnerships. This increases the level of logistics service offered to the customers and also adds value to the final product by elevating the supply chain viability.

The SCM has been recognized as a key factor to promote sustainability. Sustainability and environmental issues are among the most pressing issues in global society [27]. Furthermore, sustainability is recognized as the way in which people must interact with nature, by doing so they are recognizing the responsibility towards future generations [28].

Sustainable supply chain management is now well-known on the agenda of academic and social discussions. SSCM is defined as a strategic and transparent integration of social, environmental and economic aspects in a systemic coordination of organizational processes with the aim to improve economic performance of the company in the long run [7].

In addition, SSCM is also understood as responsible by the management of material, information and capital flows, by the means of cooperation between companies throughout the supply chain [19]. 
This is possible by adopting sustainable development goals, which are related to economic, environmental and social aspects of the supply chain, this is done with the purpose of meeting the requirements of stakeholders.

Some companies consider that the adoption of sustainability principles in supply chains creates competitive advantages [29]. Besides, SSCM can be defined as a business strategy focused on minimizing environmental, economic and social risks of the organization, that is capable to create corporate value [30]. Studies focusing on corporate orientation towards environmental issues, suggest that supply chains that focus on environmental practices in their transactions are better placed to deliver positive results [31].

The incorporation of sustainable practices in the supply chain minimizes or even avoids negative perceptions regarding environmental, social and ethical issues with the company from consumers, non-governmental organizations and public authorities [32,33]. Ref [34] corroborates this observation and adds that one of the positive benefits about the sustainability concept in the supply chain is to enhance the notion of higher product quality and the business itself. Also in this sense, it is recognized the existence of a relationship between sustainable management and the improvement in the quality of the final product [35].

Decisions taken within the supply chain reflect directly and indirectly on the other members, even if they do not recognize such facts. Thus, the importance of the sustainable supply chain management is recognized, considering that that managers need to perform the auditing and evaluation procedures of their suppliers' environmental performance metrics [36].

\section{Method}

Considering the objective of this paper, a literature review was carried out. [37] discusses modalities of literature reviews and their methodological procedures. For them, literature reviews present two perspectives: (i) Revision of topics that have accumulated knowledge and require analysis and synthesis and (ii) revision of emerging issues, whose contribution is the exposure of potential theoretical foundations, which is usually not as extensive as the first. The perspective adopted in this article fits the first notion of literature review. Taking into consideration seminal literature reviews on general contexts of sustainable supply chain management and related to green supply chain management $[12,13,16,18,38]$, we decided to cover the period of 2011-2016 in order to complement the previous studies.

It is important to point out that there are two types of literature review: (1) A narrative or traditional literature review and (2) systematic review of the literature [21]. According to the authors, the narrative review condenses the literature, but does not make explicit to the reader the established criteria for the selection of sources. In contrast, a systematic literature review is characterized by establishing clear and structured criteria in the search process and analysis of information on the subject to be investigated. For [22], this process guarantees greater rigor, robustness and replicability to the research. Therefore, it was chosen for this article, the adoption of systematic literature review (SLR) procedures.

There are several SLR protocols [22,28,39,40]. It was opted for the use of Methodi Ordinatio protocol (Figure 1), proposed by [40]. This protocol was selected because it presents a plan that goes beyond that considered the basic for the achievement of a SLR. The authors add the possibility of classifying articles from the year of publication, number of citations and the journal's impact factor in which it was published, under a multicriteria decision aid approach, so we believe that there is more rigor in this method.

The Methodi Ordinatio assists the in the decision making process regarding the choice of an article portfolio to compose a literature review. Its main advantage is to define the scientific relevance of each article using three criteria (impact factor, year of publication and the number of citations by the proposed process) instead of only one criterion (number of citations) such as, for example, the ProKnow-C (Knowledge Development Process-Constructivist) proposed by [39].

Initially, the research structure was defined, by having as a parameter the topic sustainable supply chain management. Then, a set composed by six keywords, in the English language, related to the research topic. These keywords were based on a previous exploratory search and the reading of seminal 
research. This group of words would be used for the searches, combined with the term "Supply Chain". The chosen words were: 1) Sustainability, 2) economic development, 3) environmental development, 4) social development and 5) ethical issues. The descriptor "sustainable supply chain management" was used with the Boolean operator AND. Figure 1 shows the steps of the SLR protocol.

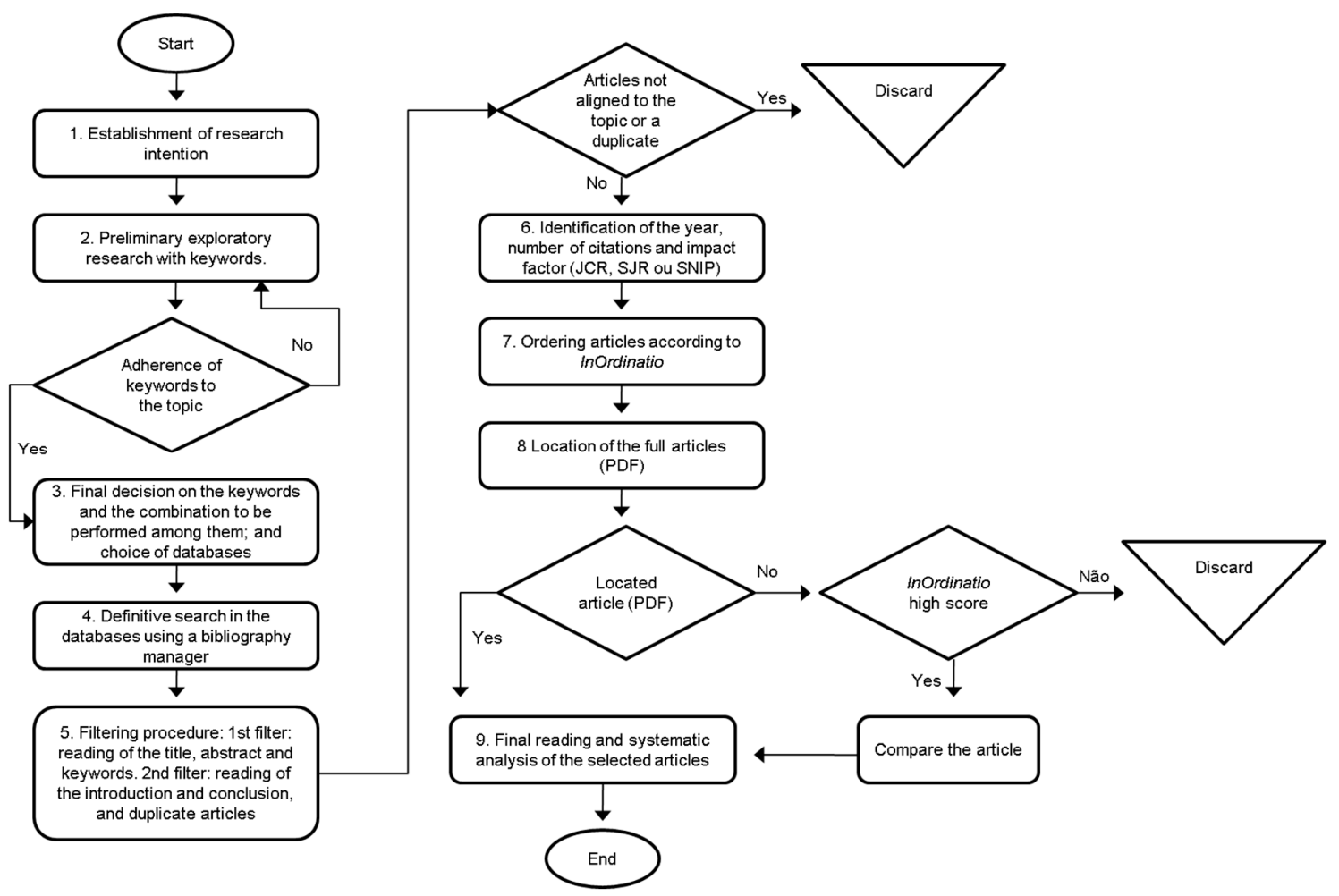

Figure 1. Application Steps of the Methodi Ordinatio methodology (Source: Adapted [32].).

Once the keywords were defined, the next step was the choice of databases. There are several databases for research [12]: Web of Science, Scopus, Science Direct Online, Emerald, Springer Link, IEEExplore, Academic Search Premier-ASP (EBSCO), Scielo, Sage Pub, Taylor \& Francis, Oxford University Press and Cambridge University Press. In this article, we selected the Web of Science, Scopus, Science Direct Online and Emerald databases, since their indexed journals have an impact factor, which is necessary data for the application of the Methodi Ordinatio (see Table 1) besides increasing the rigor of the papers selected.

A temporal cut of five years (2011 to 2016) was chosen, considering mainly the previous literature reviews published on topics related to the issue approached in this article. The search for keywords considered its appearance in the title, either in the abstract or in the keywords section

In this stage, the articles were analyzed individually using the following filters: 1) Reading of the title, abstract and keywords and 2) reading of the introduction, conclusion and exclusion of duplicate articles. From a total of 632 articles, after the application of the first filter, 119 articles remained. Subsequently, after the second filtration, 74 articles remained.

The available methods for SLR techniques provide an efficient search protocol with a sequence of parameters that allows the attainment of a portfolio of articles. However, researchers do not have any criteria to classify the quality or relevance of the article found. To satisfy this lack of criteria and metrics for article selection, the InOrdinatio calculation was applied for each work, according to the Methodi Ordinatio (Figure 1) for the next phase of this SLR. This calculation (Table 1) allowed us to order the best articles, based on the following criteria: Impact factor of the journal in which it was published, number of citations and year of publication. 
Table 1. Description of the equation used to calculate the InOrdinatio articles.

\begin{tabular}{|c|c|}
\hline Equation & Description \\
\hline$(\mathrm{IF} / 1000)+\alpha^{*}[10-($ YearSearch - YearPublished $)]+(\Sigma \mathrm{Ci})$ & $\begin{array}{l}\text { - IF: Impact factor, as defined by the Journal } \\
\text { Citation Report (JCR); } \\
\text { - } \quad \alpha \text { : Coefficient of importance of the publication } \\
\text { year factor, varying from } 1 \text { to } 10 \text {; } \\
\text { - YearSearch: Year in which the survey was } \\
\text { being conducted } \\
\text { - YearPublished: Publication year of the article } \\
\text { - } \quad \Sigma \text { Ci: Total citations in the article }\end{array}$ \\
\hline
\end{tabular}

Source: [40].

As Table 1, the impact factor (IF) value was divided by 1000 (thousand) in order to normalize its value over the other criteria. For setting the value of alpha $(\alpha)$, which is a weighting factor ranging from 1 to 10 to be assigned by the investigator, tests were made using values $1,3,5,7$ and 10. It was noticed that the intermediate values ( 3 and 7 ) were not significant in the calculation, that is, they had little influence on the classification. The extreme values (1 and 10) have made the final value too low or too high, eliminating relevant works or including works that did not meet the previously established criteria. Thus, for this work, the alpha chosen was defined as the value 5 , seeking a better balance between the three analysis factors.

The articles remaining from the second filtering process (74) were ordered via InOrdinatio. [40] recommended the systematic reading of the articles that presents InOrdinatio within a relevant range, to be delimited by the researcher, himself, using his sensitivity in relation to the researched topic. In this case, the first 34 articles were selected, which presented InOrdinatio superior to 90 . This selection considered that the works with index below 90 were "distant" from the others, mainly, in terms of impact factor of the periodical and year of publication. Figure 2 presents the results of the filters referring to the systematic review of the literature.

Besides to characterize the articles analyzed in terms of the distribution of publications per year, main methods adopted, main journals of publication and related to the approach of the sustainability dimensions, we used the categorical thematic content analysis technique in order to perform an in depth analysis of the articles. We analyzed the sections of "suggestions for future works" and "research agendas", besides "concluding remarks" or "final considerations" of the articles, in order to identify a research agenda on SSCM.

The "content analysis can be considered as a set of communication analysis techniques, which uses systematic procedures and objective descriptions of the contents of messages" [41] p. 38. In addition, this protocol comprises the following steps: I) Reading of the collected material, II) codification for the formulation of analysis categories, III) clipping of the material (in units of record, such as words, phrases and paragraphs, comparable and with the same semantic content), IV) establishment of categories, V) grouping of registration units into common categories, VI) progressive grouping of categories (initial, intermediate and final, respectively) and VII) inference and interpretation [36].

Following the steps proposed, the data of the articles' portfolio selected for this research were analyzed through a construction process of categories or themes, which aim to capture repeated patterns in most of the collected data. The categories were created a posteriori, according to the directions senses of the articles' sections analyzed. It was also verified the repetition of some elements, which guided the creation of categories. 


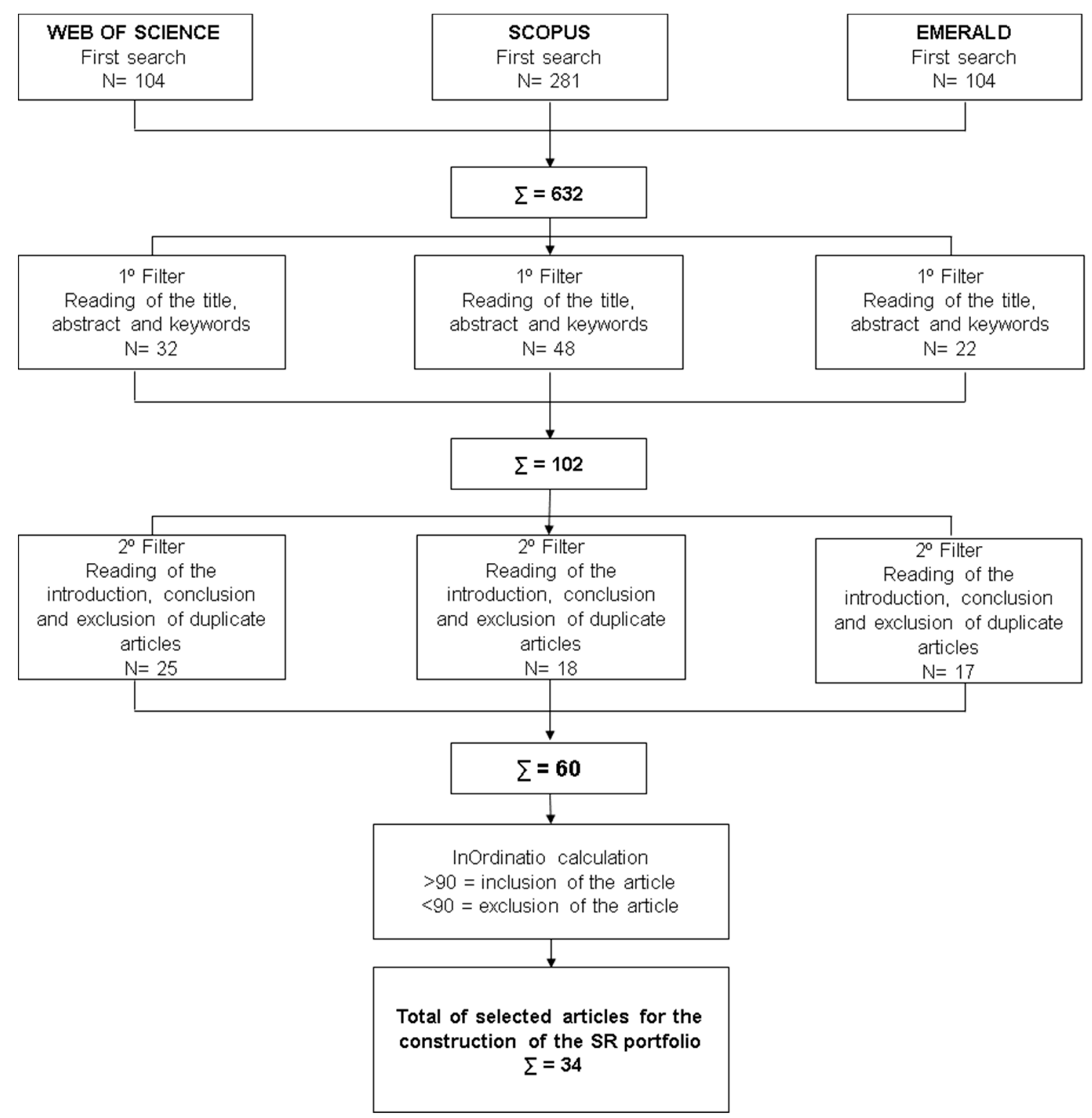

Figure 2. Filter Results of the systematic review of the literature.

\section{Results: The General Context of the Publications}

The purpose of this section was to point out the current status of SSCM researches selected following the steps of this SLR. The next step was a reflection of the analysis of a portfolio of papers obtained in international databases, as mentioned in the previous section. The context presented was based on the adopted methods, countries in which they were applied, publication journals and dimensions of sustainable development [2]: Environmental, social and economic development and, when integrated and balanced, can reach sustainability.

Based on the methods adopted in the development of the articles, the classification was based on an adaptation of the [18] proposal. In this study, the authors classify the articles, based on the methodology used, in theoretical and conceptual studies, case studies, surveys, modeling and literature reviews. In this case, the articles of a bibliographic nature or literature review were excluded because the assumptions of systematic literature reviews presuppose the inclusion of empirical research only [21]. The authors also propose that in cases of articles that present more than one type of methodological procedure, these should be classified according to the main methodology. Figure 3 shows the result of this classification. 
In general, it was noted that the studies analyzed use numerous scientific investigation methods. Modeling was the main method employed, followed by the case study (single and multiple). In the case of the articles that used modeling, it was verified that a considerable part of these (8) adopted the data envelopment analysis (DEA). DEA is a mathematical programming technique that seeks to analyze the performance, in terms of the relative efficiency, of different decision-making units (DMUs), from a set of inputs and outputs [42,43].

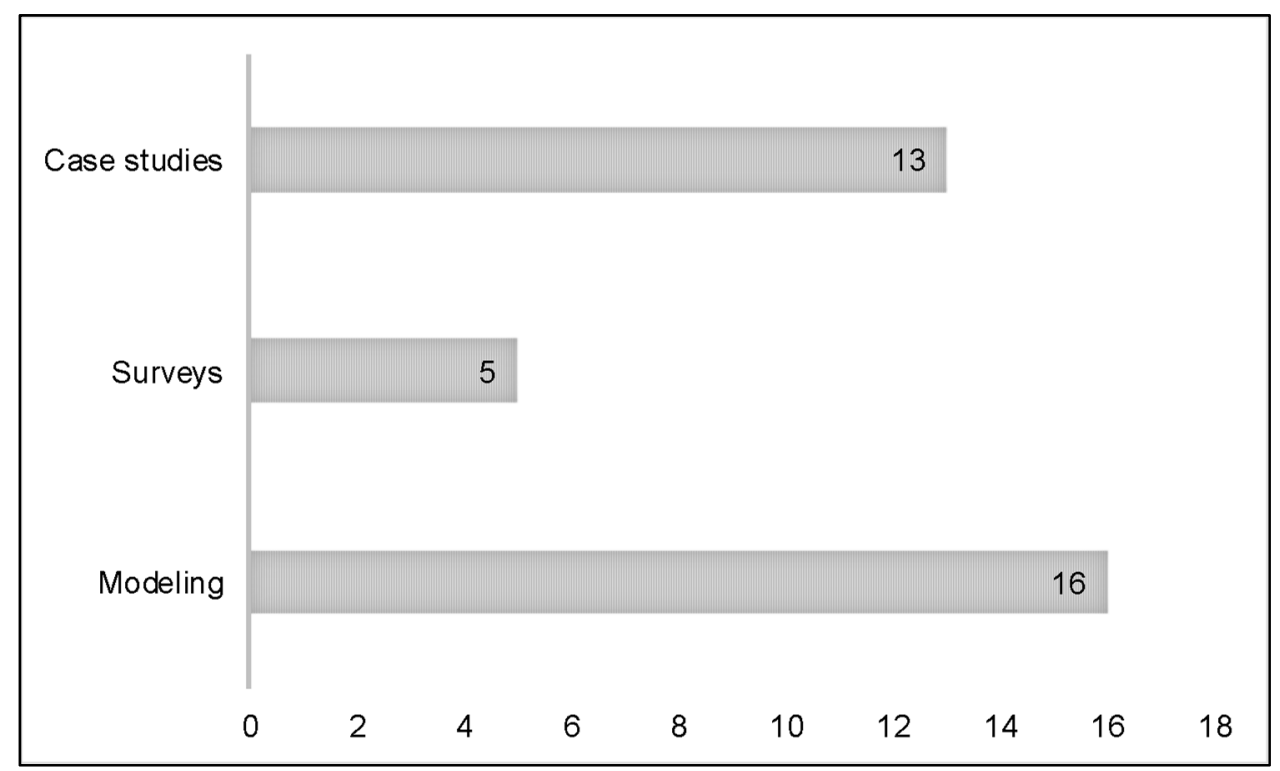

Figure 3. Classification of papers on the main method adopted.

The incorporation of sustainability aspects in SC is still an uncommon practice in most organizations, especially in emerging countries [44]. Thus, the data is consistent regarding case studies and surveys. Consequently, it is understandable that purely theoretical and conceptual studies tend to diminish over time, as long as the theme becomes consolidated.

In addition, it was noted that research on SSCM adopts a diversified number of research methods and that there is no predominant approach. Such a situation can be better understood when it is taken into account the multidisciplinary nature of the research involving this field, which comprises several themes and sectors of the economy, besides, in general, they are studied with different theoretical perspectives.

It was also observed that the analyzed studies adopted qualitative approaches (34\%) and had a strong predominance of quantitative approaches $(50 \%)$. A smaller percentage $(16 \%)$ combined the two approaches, constituting the mixed methodology. It was also noted that a considerable portion of the articles with elevated indexes InOrdinatio, published in the years considered in this SLR, are from the United States of America (7), followed by India (5). It is worth stressing that the USA pioneered researches on SSCM. The scientific contributions of Malaysia (4) and United Kingdom (3) are also noteworthy.

It can be seen that of the first four, only the United States of America and the United Kingdom are classified as developed countries where, it is expected to find greater stimulation and investments for scientific research. However, India and Malaysia, despite being emerging countries, have made a significant contribution with works with a high impact factor on SSCM, in comparison with a large and developed economy such as the USA.

It must be acknowledged that the political environment may change in some countries and governments, although timidly, may have the conditions to introduce increasingly rigid regulation covering environmental aspects [45]. In general, it is known that these regulations do not take place only in developed countries. Brazil is in this scenario with rigorous environmental crime laws and an 
advanced solid waste policy. Apart from that, the resolutions of environmental agencies are known to be strict. It was observed, however that the number of high-level publications in the SSCM field has no relation to whether or not the country has a regulatory framework regarding sustainability aspects. As a result, at the supply chain level, focal companies would need to cooperate with other parties in networks, which is done in accordance with governments and regulatory agencies [46-48].

It is also important to highlight the economy sectors in which these important works have been developed. The automotive sector stands out in this sense with six publications. This fact is expected, since this sector has an extensive and complex supply chain and this may, in theory, stimulate greater interest of the researchers and the pioneers in adopting brand-new concepts and strategies. It is also worth noting the food sector (4) and the metallurgical sector (3). Regardless of the industry, there are suggestions that if firms want to be competitive and survive in markets, they need to broaden their activities focused on the principles of sustainability [49].

An amount of articles was not classified in any sector considering the absence of information related to it, some articles only pointed out some characteristics of the company surveyed, as for example, the size (small and medium companies) and companies with environmental certification, among others.

Another element to be pointed out is related to the journals in which the articles were published. Noteworthy, there is a predominance of the Journal of Cleaner Production and the International Journal of Physical Distribution of Logistics Management. Table 2 presents this distribution of the works related to journal of publication.

Table 2. Distribution of articles on the publication of journals.

\begin{tabular}{cc}
\hline Journals & $\mathbf{N}^{\mathbf{o}}$ of articles \\
\hline Journal of Cleaner Production & 7 \\
International Journal of Physical Distribution of Logistics Management & 4 \\
British Food Journal & 3 \\
International Journal of Operations \& Production Management & 2 \\
Resources Conservation and Recycling & 2 \\
International Journal of Quality \& Reliability Management & 2 \\
Supply Chain Management: An International Journal & 2 \\
Other Journals & 12 \\
Total & 34 \\
\hline
\end{tabular}

Analyzing the year of publication of the selected articles, Figure 4 presents a graphical distribution where it can be seen that the systemic analysis of the approaches (total integration), that is, environmental, economic and social, overlaps with the others, indicating a "complete" sustainable approach, as advocated by [2]. Partial integration refers to works that have addressed two dimensions, for example, economic and environmental or economic and social.

It is also important to highlight the evolution of studies focusing on the social dimension, especially in 2016. This indicates that social issues are being the focus of SSCM researches. It is also interesting to note a small number of articles focused solely on the economic aspect.

Most of the existing literature considers only the environmental aspects of sustainability [50-52]. It is necessary to consider the social factors, besides the environmental and economic impacts, in order to analyze the supply chains from the perspective of sustainability, since this type of analysis presupposes a balance between the three dimensions. 


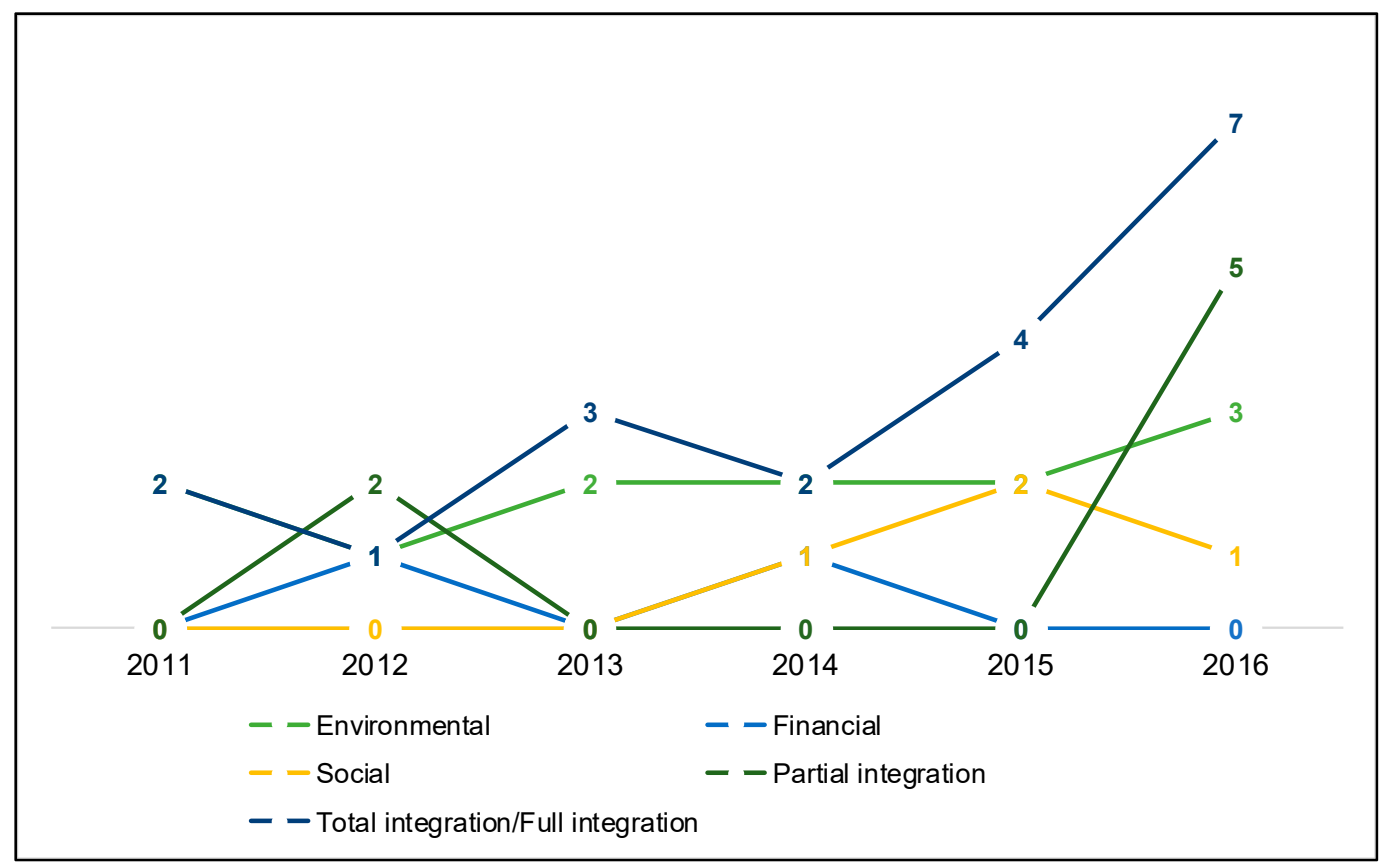

Figure 4. Approach of the dimensions of sustainability.

\section{The Dimensions of Sustainability and its Discussions in the Articles Analyzed}

The concern regarding sustainable development has spread [45]. The authors recognize that, currently, sustainability is seen as a source of competitive advantage. It is imperative that sustainability approaches be incorporated into the dynamics of supply chains.

The dimensions of sustainability analyzed in a supply chain are based on some approaches, among which it can be highlighted the environmental, economic, social, political and educational approach. For the purpose of this article, only the first three were adopted, which stem from the triple bottom line concept proposed by [2]. The strategic integration of these dimensions in the systemic coordination of the inter-organizational business processes (SSCM), provides an improvement in the long-term economic performance of the individual company and its supply chain [7].

In order to have a holistic approach to supply chain sustainability and a comprehension of the mechanisms involved in sustainable product supply, researchers need to include some sustainability dimensions such as economic, environmental and social [53]. Some authors reinforce that sustainability performance in a supply chain can only be dimensioned with the performance measured in all sustainability dimensions [49].

The incorporation of sustainable requirements into supply chain is justified in part by the increased consumer awareness of environmental and social issues, stricter environmental laws and regulations and the search for competitiveness in markets, which seeks to find a competitive advantage over the competitors [54-56].

It is also interesting to note that some studies have verified, directly or indirectly, that some companies consider the adoption of sustainability solely for the purpose of creating a competitive advantage $[57,58]$. The fact is that sustainable strategies in the supply chain have become the backbone of many companies, embedded in a socially and environmentally sensitive business environment.

\section{Future Perspectives: A Research Agenda}

Based on the evidence found in this study and from the content analysis of future research proposals identified in the articles analyzed, it was possible to verify some research gaps in this field, which can guide researchers and practitioners. 
A priori, four categories were created from the content analysis of the suggestions for future research issues presented in the analyzed articles. These categories address thematic issues frequently cited in this section of the papers. Based on the analysis of Table 3 and on the subsequent contextualization with the data of this article as a whole, it is possible to establish a research agenda in this field of knowledge. Next, a brief description of each thematic possibilities that can be exploited in the future:

Table 3. Categorization of the articles analyzed.

\begin{tabular}{|c|c|c|}
\hline Category & Description & Works that support the category \\
\hline $\begin{array}{l}\text { Holistic view of } \\
\text { sustainability }\end{array}$ & $\begin{array}{l}\text { The holistic view on the SSCM, } \\
\text { comprising environmental, } \\
\text { economic and social factors. }\end{array}$ & $\begin{array}{l}\text { (Bask et al., 2013); (Fabbe-Costes et al., 2011); } \\
\text { (Walker and Jones, 2012); (Brandenburg et al., } \\
\text { 2014); (Touboulic; Walker, 2015); (Metin Türkay, } \\
\text { Öztürk Saraçoğlu, 2016); (Mellat-Parast, 2013); } \\
\text { (Su et al., 2015); (Kumar and Rahman, 2016); } \\
\text { (Frostenson and Prenkert, 2015) }\end{array}$ \\
\hline $\begin{array}{l}\text { SSCM as an emerging } \\
\text { research field }\end{array}$ & $\begin{array}{l}\text { To be competitive, the companies, } \\
\text { in the current context need to } \\
\text { adopt sustainable practices as a } \\
\text { way to broaden their scope of } \\
\text { action throughout the SC. }\end{array}$ & $\begin{array}{l}\text { (Mariadoss et al., 2016); (Alshubiri and Hussein, } \\
\text { 2016); (Wichmann and Kaufmann, 2016); } \\
\text { (Izadikhah; Farzipoor Saen, 2016); (Singh et al., } \\
\text { 2016); (Günther et al., 2015) }\end{array}$ \\
\hline $\begin{array}{l}\text { Detailed approach of the } \\
\text { social dimension }\end{array}$ & $\begin{array}{l}\text { The studies that deal with } \\
\text { sustainability in SC focus mostly } \\
\text { on environmental and economic } \\
\text { dimensions. However, it must also } \\
\text { consider the social, environmental } \\
\text { and economic impacts }\end{array}$ & $\begin{array}{c}\text { (Izadikhah and Farzipoor Saen, 2016); } \\
\text { (Simangunsong, Hendry and Stevenson, 2016); } \\
\text { (Mani et al., 2016); (Venkatesh Mani et al., 2016); }\end{array}$ \\
\hline $\begin{array}{l}\text { Detailed approach of the } \\
\text { environmental dimension }\end{array}$ & $\begin{array}{l}\text { Considering the consumer } \\
\text { awareness of environmental } \\
\text { issues, environmental laws and } \\
\text { stricter regulations, it is necessary } \\
\text { to broaden the discussion about } \\
\text { this dimension in the SC. }\end{array}$ & $\begin{array}{c}\text { (Wu, 2013); (Kotzab et al., 2011); (Kaipia, } \\
\text { Dukovska-Popovska and Loikkanen, 2013); } \\
\text { (Günther, Kannegiesser and Autenrieb, 2015); } \\
\text { (Leigh and Li, 2015); (Shaharudin et al., 2015); } \\
\text { (Formentini and Taticchi, 2016); (Hsu, 2013); } \\
\text { (Green Jr et al., 2012). }\end{array}$ \\
\hline
\end{tabular}

Based on the categories above, one can build a research agenda as guidance for future research that will be developed from this theme.

Holistic view of sustainability: It is necessary to address the issue of SC sustainability in a holistic, systemic way, encompassing the economic, environmental and social dimensions. Extending this type of analysis to previously unexplored sectors would also be fundamental (see Table 1).

1. SSCM as an emerging research field: It is necessary to broaden the scientific research, in general, in the subject of SSCM. The authors who support this statement recognize that, in order to be competitive, companies need to adopt sustainable practices as a way to broaden their scope of action throughout the supply chain. Scientific research can substantially contribute to this issue.

2. Detailed approach of the social dimension: Through the analysis of the data presented in this work, it is noticeable that few studies have addressed social issues in the discussions about supply sustainability. The fact, the social aspect still is a considerable research gap in this area.

3. Detailed approach of the environmental dimension: Although it is clear that a large portion of the SSCM researches addresses the environmental issue of the problem, authors that were analyzed in this paper suggest that discussions involving this dimension should be expanded. Mathematical modeling has often been recognized as an interesting method to be used in this case, especially the DEA, which is the most employed method. However, other approaches such as the multiple criteria decision aid (MCDA) are adequate to deal with decision problems related to SSCM, since they can make use of multiple qualitative and quantitative criteria. The data envelopment analysis (DEA) allows the use of multiple inputs and outputs to identify some assumptions about the efficiency. This model can consider the environmental and social impacts for this purpose, reaching a set of optimal solutions to be indicated and analyzed [43]. 


\section{Final Remarks and Contributions}

This work sought to synthesize the high-quality publications about the SSCM, highlighting the sustainability dimensions addressed, sectors most studied methods used, distribution per year and main countries and journals of publications. The final aim was to contribute to the guidance of future research in this subject by identifying possible research gaps and by proposing a research agenda.

In general, it was found that the analyzed articles make use of several investigation methods, with mathematical modeling as the most used among these, followed by the case study (single or multiple). It can be said that regarding the method there was a clear predominance of quantitative studies, although the qualitative methods were also common. The analyzed supply chains were mostly installed in the USA and India and were related to sectors such as automotive, food and metallurgy, which were indicated as the most studied.

Regarding the sustainability dimensions, it was verified that the total integration, which means the balance among environmental, economic and social integration, overlaps with the others, indicating a sustainable holistic approach present in most studies. The evolution of studies focusing on the social dimension is also noteworthy, especially in 2016. This indicates that social issues are becoming the focus of SSCM research.

As limiting factors of the study, it is possible to highlight the temporal cut of only five years, as the extension of this period could yield different results. The research was also limited to the use of a specific protocol for systematic review, the Methodi Ordinatio. If other protocols were employed, and because they consider different criteria for filtering the articles, they would probably generate a diverse result. It is also important to emphasize the limitation imposed by the definition of the inclusion/exclusion interval of the articles that was based on the InOrdinatio values. In this application method step, if the researcher does not take the necessary precautions, he may end up leaving out of the analysis of articles that could broaden the discussion proposed.

Besides that, we can point out that this paper does not analyze in depth the integration of the sustainability dimensions, nor apply other methodological possibilities, such as, case study, survey, documental analysis and modeling. The purpose lies only in the identification of the main research gaps in the period considered for this SLR.

This article, by synthesizing the high-quality literature produced in the period 2011-2016 and by choosing sound articles with the Methodi Ordinatio protocol, can contribute to guiding future research that will be developed in this field of knowledge. It is important to recognize that SSCM is a topic debated by international journals with a high impact factor in recent years. By highlighting which dimensions of sustainability are being addressed in high-level scientific papers, as well as the general context of the analyses proposed by these articles, this article contributes to the identification of possible research gaps that may guide researchers in the area.

It is suggested that future research may include the following issues: To address the subject of supply chain sustainability in a holistic, systemic way, including the economic, environmental and social dimensions. There is also an opportunity to extend this type of analysis to sectors that are receiving poor attention; and to broaden the analysis focused on the social and environmental issues, as it was clear that these approaches are emerging within the SSCM scope and that they need to be scientifically examined. In addition, further systematic reviews based on other protocols, such as $[14,15]$.

We also suggest the use of some different protocol to validate the final sample of selected papers. The extension of the period analyzed, the journal databases and the consideration of other types of impact indicators can be part of other studies. In addition, we suggest systematic literature reviews of the strategies categorized in Table 3. Future studies using quantitative approaches, such as surveys and/or proposing frameworks based on mathematical, econometric, problem-structuring or multi-criteria approaches to support decisions including the sustainability dimensions, can also be useful. Furthermore, all the suggestions provided in Table 3, Section 6 can guide researchers indicating a path for future agenda. 
Author Contributions: The author W.H.S. carried out the search, filtering process and analysis of articles considered for this SLR, besides the conceptualization and writing. The author P.G. contributed in the conceptualization, analysis of papers selected for the SLR, writing and original draft preparation, writing review and editing of the manuscript. The author J.M.C. contributed in the writing and review and editing. The author J.S.F. contributed on the analysis of papers selected for this SLR, review and editing. The author S.A.R. contributed in the writing review and editing.

Funding: This research received no external funding.

Acknowledgments: We acknowledge the Brazilian Coordination of Improvement of Higher-Level Personnel, which supported part of this research.

Conflicts of Interest: The authors declare no conflict of interest.

\section{References}

1. Wilhelm, M.M.; Blome, C.; Bhakoo, V.; Paulraj, A. Sustainability in multi-tier supply chains: Understanding the double agency role of the first-tier supplier. J. Oper. Manag. 2016, 41, 42-60. [CrossRef]

2. Elkington, J. Towards the sustainable corporation: Win-win-win business strategies for sustainable development. Calif. Manag. Rev. 1994, 36, 90-100. [CrossRef]

3. SACHS. Ignacy. Estratégias de Transição para o século XXI-Desenvolvimento e meio Ambiente; Studio Nobel/Fundap: São Paulo, Brazil, 1993.

4. Zailani, S.; Jeyaraman, K.; Vengadasan, G.; Premkumar, R. Sustainable supply chain management (SSCM) in Malaysia: A survey. Int. J. Prod. Econ. 2012, 140, 330-340. [CrossRef]

5. Tang, C.S.; Zhou, S. Research advances in environmentally and socially sustainable operations. Eur. J. Oper. Res. 2012, 223, 585-594. [CrossRef]

6. Green, K.W., Jr.; Zelbst, P.J.; Meacham, J.; Bhadauria, V.S. Green supply chain management practices: Impact on performance. Supply Chain Manag. Int. J. 2012, 17, 290-305. [CrossRef]

7. Carter, C.R.; Rogers, D.S. A framework of sustainable supply chain management: Moving toward new theory. Int. J. Phys. Distrib. Logist. Manag. 2008, 38, 360-387. [CrossRef]

8. Croom, S.; Vidal, N.; Spetic, W.; Marshall, D.; McCarthy, L. Impact of social sustainability orientation and supply chain practices on operational performance. Int. J. Oper. Prod. Manag. 2018, 38, 2344-2366. [CrossRef]

9. Marshall, D.; McCarthy, L.; Heavey, C.; McGrath, P. Environmental and social supply chain management sustainability practices: Construct development and measurement. Prod. Plan. Control 2015, 8, 673-690. [CrossRef]

10. Min, H.; Kim, I. Green supply chain research: Past, present, and future. Logist. Res. 2012, 4, 39-47. [CrossRef]

11. Kashav, S.; Cerchione, R.; Centobelli, P.; Shabani, A. Sustainability orientation, supply chain integration, and SMEs performance: A causal analysis. Benchmarking Int. J. 2018, 25, 3679-3701.

12. Fahimnia, B.; Sarkis, J.; Davarzani, H. Green supply chain management: A review and bibliometric analysis. Int. J. Prod. Econ. 2015, 162, 101-114. [CrossRef]

13. Chin, T.A.; Tat, H.H.; Sulaiman, Z. Green supply chain management, environmental collaboration and sustainability performance. Procedia CIRP 2015, 26, 695-699. [CrossRef]

14. Centobelli, P.; Cerchione, R.; Esposito, E. Environmental sustainability in the service industry of transportation and logistics service providers: Systematic literature review and research directions. Transp. Res. Part D Transp. Environ. 2017, 53, 454-470. [CrossRef]

15. Centobelli, P.; Cerchione, R.; Esposito, E. Knowledge management in startups: Systematic literature review and future research agenda. Sustainability 2017, 9, 361. [CrossRef]

16. Jin, Z.; Navare, J.; Lynch, R. The relationship between innovation culture and innovation outcomes: Exploring the effects of sustainability orientation and firm size. RD Manag. 2018. [CrossRef]

17. Brandenburg, M.; Govindan, K.; Sarkis, J.; Seuring, S. Quantitative models for sustainable supply chain management: Developments and directions. Eur. J. Oper. Res. 2014, 233, 299-312. [CrossRef]

18. Seuring, S.; Müller, M. From a literature review to a conceptual framework for sustainable supply chain management. J. Clean. Prod. 2008, 16, 1699-1710. [CrossRef]

19. Sarkis, J.; Zhu, Q.; Lai, K.H. An organizational theoretic review of green supply chain management literature. Int. J. Prod. Econ. 2011, 130, 1-15. [CrossRef]

20. Gold, S.; Seuring, S.; Beske, P. Sustainable supply chain management and inter-organizational resources: A literature review. Corp. Soc. Responsib. Environ. Manag. 2010, 17, 230-245. [CrossRef] 
21. Cronin, P.; Ryan, F.; Coughlan, M. Undertaking a literature review: A step-by-step approach. Br. J. Nurs. 2008, 17, 38-43. [CrossRef]

22. Denyer, D.; Tranfield, D. Producing a systematic review. In The Sage Hand Book of Organizational Research Methods; Buchanan, D.A., Bryman, A., Eds.; Sage Publications: London, UK, 2009; pp. 671-689.

23. Lambert, D.M.; Cooper, M.C.; Pagh, J.D. Supply chain management: Implementation issues and research opportunities. Int. J. Logist. Manag. 1998, 9, 1-20. [CrossRef]

24. Mentzer, J.T.; DeWitt, W.; Keebler, J.S.; Min, S.; Nix, N.W.; Smith, C.D.; Zacharia, Z.G. Defining supply chain management. J. Bus. Logist. 2001, 22, 1-25. [CrossRef]

25. Chopra, S.; Meindl, P. Supply chain management. Strategy, planning \& operation. In Das Summa Summarum des Management; Pearson: London, UK, 2007; pp. 265-275.

26. Cooper, M.C.; Lambert, D.M.; Pagh, J.D. Supply chain management: More than a new name for logistics. Int. J. Logist. Manag. 1997, 8, 1-14. [CrossRef]

27. Hsu, C.C.; Choon Tan, K.; Hanim Mohamad Zailani, S.; Jayaraman, V. Supply chain drivers that foster the development of green initiatives in an emerging economy. Int. J. Oper. Prod. Manag. 2013, 33, 656-688. [CrossRef]

28. Ayres, R.U. Sustainability economics: Where do we stand? Ecol. Econ. 2008, 67, 281-310. [CrossRef]

29. Clemens, B.; Douglas, T.J. Does coercion drive firms to adopt 'voluntary'green initiatives? Relationships among coercion, superior firm resources, and voluntary green initiatives. J. Bus. Res. 2006, 59, 483-491. [CrossRef]

30. Wang, W.C.; Teng, J.T.; Lou, K.R. Seller's optimal credit period and cycle time in a supply chain for deteriorating items with maximum lifetime. Eur. J. Oper. Res. 2014, 232, 315-321. [CrossRef]

31. Stone, G.; Wakefield, K. Eco-orientation: An extension of market orientation in an environmental context. J. Mark. Theory Pract. 2011, 8, 21-31. [CrossRef]

32. Hoejmose, S.U.; Roehrich, J.K.; Grosvold, J. Is doing more doing better? The relationship between responsible supply chain management and corporate reputation. Ind. Mark. Manag. 2014, 43, 77-80. [CrossRef]

33. Maloni, M.; Brown, M. Corporate social responsibility in the supply chain: An application in the food industry. J. Bus. Ethics 2006, 68, 35-52. [CrossRef]

34. Tate, W.L.; Ellram, L.M.; Kirchoff, J.F. Corporate social responsibility reports: A thematic analysis related to supply chain management. J. Supply Chain Manag. 2010, 46, 19-44. [CrossRef]

35. Curkovic, S.; Melnyk, S.A.; Handfield, R.B.; Calantone, R. Investigating the linkage between total quality management and environmentally responsible manufacturing. IEEE Trans. Eng. Manag. 2000, 47, 444-464. [CrossRef]

36. Handfield, R.; Sroufe, R.; Walton, S. Integrating environmental management and supply chain strategies. Bus. Strategy Environ. 2005, 14, 1-19. [CrossRef]

37. Webster, J.; Watson, R.T. Analyzing the past to prepare for the future: Writing a literature review. MIS $Q$. 2002, 26, xiii-xxiii.

38. Higgins, J.P.; Green, S. The Cochrane Collaboration. In Cochrane Handbook for Systematic Reviews of Interventions; Wiley Online Library: Chichester, West Sussex, England, 2011.

39. Rosa, F.S.; Ensslin, S.R.; Ensslin, L. Environmental evidence: A structured process of literature review on performance evaluation of environmental disclosure. Management Decision 2012, 50, 1117-1136.

40. Pagani, R.N.; Kovaleski, J.L.; Resende, L.M. Methodi Ordinatio: A proposed methodology to select and rank relevant scientific papers encompassing the impact factor, number of citation, and year of publication. Scientometrics 2015, 105, 2109-2135. [CrossRef]

41. Bardin, L. Analysis of Content; Edição: Lisbon, Portugal, 1977; p. 70.

42. Forsund, F.R.; Sarafoglou, N. On the origins of data envelopment analysis. J. Product. Anal. 2002, 17, $23-40$. [CrossRef]

43. Rosano-Peña, C.; Guarnieri, P.; Sobreiro, V.A.; Serrano, A.L.M.; Kimura, H. A measure of sustainability of Brazilian agribusiness using directional distance functions and data envelopment analysis. Int. J. Sustain. Dev. World Ecol. 2014, 21, 210-222. [CrossRef]

44. Mathiyazhagan, K.; Govindan, K.; Noorul Haq, A. Pressure analysis for green supply chain management implementation in Indian industries using analytic hierarchy process. Int. J. Prod. Res. 2014, 52, 188-202. [CrossRef] 
45. Fabbe-Costes, N.; Roussat, C.; Colin, J. Future sustainable supply chains: What should companies scan? Int. J. Phys. Distrib. Logist. Manag. 2011, 3, 228-252. [CrossRef]

46. Mariadoss, B.J.; Chi, T.; Tansuhaj, P.; Pomirleanu, N. Influences of firm orientations on sustainable supply chain management. J. Bus. Res. 2016, 69, 3406-3414. [CrossRef]

47. Alshubiri, F.N.; Hussein, M.A. Investigating the Impact of Sustainable Development Supply Chain on Economic Performance: An Empirical Study of Sultanate of Oman. Int. J. Supply Chain Manag. 2016, 5, 69-81.

48. Wichmann, B.K.; Kaufmann, L. Social network analysis in supply chain management research. Int. J. Phys. Distrib. Logist. Manag. 2016, 46, 740-762. [CrossRef]

49. Schaltegger, S.; Wagner, M. Integrative management of sustainability performance, measurement and reporting. Int. J. Account. Audit. Perform. Eval. 2006, 3, 1-19. [CrossRef]

50. Izadikhah, M.; Saen, R.F. Evaluating sustainability of supply chains by two-stage range directional measure in the presence of negative data. Transp. Res. Part D Transp. Environ. 2016, 49, 110-126. [CrossRef]

51. Simangunsong, E.; Hendry, L.C.; Stevenson, M. Managing supply chain uncertainty with emerging ethical issues. Int. J. Oper. Prod. Manag. 2016, 36, 1272-1307. [CrossRef]

52. Mani, V.; Gunasekaran, A.; Papadopoulos, T.; Hazen, B.; Dubey, R. Supply chain social sustainability for developing nations: Evidence from India. Resour. Conserv. Recycl. 2016, 111, 42-52. [CrossRef]

53. Jakhar, S.K. Performance evaluation and a flow allocation decision model for a sustainable supply chain of an apparel industry. J. Clean. Prod. 2015, 87, 391-413. [CrossRef]

54. Su, C.M.; Horng, D.J.; Tseng, M.L.; Chiu, A.S.; Wu, K.J.; Chen, H.P. Improving sustainable supply chain management using a novel hierarchical grey-DEMATEL approach. J. Clean. Prod. 2015, 134, 469-481. [CrossRef]

55. Kumar, D.; Rahman, Z. Buyer supplier relationship and supply chain sustainability: Empirical study of Indian automobile industry. J. Clean. Prod. 2016, 131, 836-848. [CrossRef]

56. Frostenson, M.; Prenkert, F. Sustainable supply chain management when focal firms are complex: A network perspective. J. Clean. Prod. 2015, 107, 85-94. [CrossRef]

57. Wu, G.C. The influence of green supply chain integration and environmental uncertainty on green innovation in Taiwan's IT industry. Supply Chain Manag. Int. J. 2013, 18, 539-552. [CrossRef]

58. Kotzab, H.; Munch, H.M.; de Faultrier, B.; Teller, C. Environmental retail supply chains: When global Goliaths become environmental Davids. Int. J. Retail Distrib. Manag. 2011, 39, 658-681. [CrossRef] 